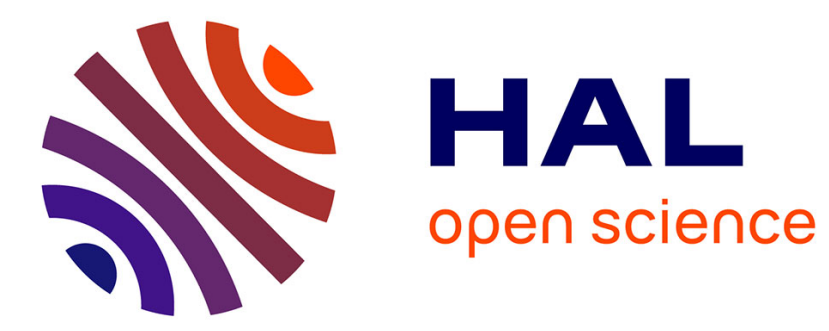

\title{
Measurement of the dynamic fracture toughness with notched PMMA specimen under impact loading
}

Sohbi Sahraoui, Abderrahim El Mahi, Bernard Castagnede

\section{To cite this version:}

Sohbi Sahraoui, Abderrahim El Mahi, Bernard Castagnede. Measurement of the dynamic fracture toughness with notched PMMA specimen under impact loading. Polymer Testing, 2009, 28 (7), pp.780-783. 10.1016/j.polymertesting.2009.06.005 . hal-00433863

\section{HAL Id: hal-00433863 https://hal.science/hal-00433863}

Submitted on 20 Nov 2009

HAL is a multi-disciplinary open access archive for the deposit and dissemination of scientific research documents, whether they are published or not. The documents may come from teaching and research institutions in France or abroad, or from public or private research centers.
L'archive ouverte pluridisciplinaire HAL, est destinée au dépôt et à la diffusion de documents scientifiques de niveau recherche, publiés ou non, émanant des établissements d'enseignement et de recherche français ou étrangers, des laboratoires publics ou privés. 


\title{
Measurement of the dynamic fracture toughness with notched PMMA specimen under impact loading.
}

\author{
S. Sahraoui(*), A. El Mahi and B. Castagnède \\ Laboratoire d'Acoustique de l'Université du Maine, UMR CNRS 6613 \\ Avenue O. Messiaen, 72085 Le Mans Cedex 9 (France)
}

\begin{abstract}
In the present study three-point-bend impact experiments were conducted using an instrumented Charpy pendulum with a laser displacement measurement to better understand the correlation between impact velocity and the dynamic effects observed on the load-time curves. The experiments were performed at impact velocities ranging from 1 to $4 \mathrm{~m} / \mathrm{s}$.

The aim of this work is to measure the dynamic fracture toughness at high impact velocities where the classical method is limited by the inertial effects. The direct measurements of the specimen deflection are successfully used for the toughness evaluation. The results obtained with this method, which are compared to other studies, indicate that this approach seems promising for brittle materials such as PMMA.
\end{abstract}

keywords : toughness, impact, dynamic effects, brittle fracture, PMMA

\section{1 - Introduction}

The mechanical properties of most materials are sensitive to loading rate and the fracture toughness under dynamic loading has received considerable attention [1].

The instrumented impact loading test is rapidly being accepted as a useful tool for evaluating the dynamic response of materials. The modern instrumentation has overcome many of the practical limitations and some studies were focused on electronic devices recommendations [2].

The effects of inertial loading in Charpy tests have been studied by many authors. The dynamic effects were analysed through various modelisations: spring system [3,4], EulerBernoulli equation [5], finite element method [6],...The aim of these investigations is to give a simple interpretation of the load-time traces observed during the instrumented impact testing and then to determine the effects of inertial loading.

A procedure obtained from pre-established impact response curve and a measurement of the time-to-fracture were proposed by Kalthoff [7\}. The measuring technique is fully dynamic and does not impose any restrictions on the test conditions. This is precisely the objective of the present paper. In fact, we use the classical instrumentation for measuring the impact load and we introduce a novel procedure for determining the dynamic toughness through the specimen deflection measurement by mean of a laser vibrometer. This method can be applied for brittle materials (PMMA in the present study) where the instable fracture can be easily observed on the load-time curve. The direct measurement of the specimen deflection may overcome the inertial effects which are not perturbing the displacement-time curve. The

$(*)$ corresponding author:

email address : sohbi.sahraoui@univ-lemans.fr 
determination of the deflection at the fracture initiation during the impact can be considered as good information in the Charpy test. At high velocity, the load-time curves are not exploitable due to the presence of inertial effects, but the calculations with the present method give similar results as Theocaris [8]. Concluding remarks and prospective discussion are given in the end of this paper.

\section{2 - Experimental method}

The Charpy pendulum (Zwick 7.5J) is instrumented by strain gages for measuring the load applied on the three point bending specimen of which the deflection is obtained through the laser vibrometer (Polytec OFV302) as indicated on Fig. 1. The load-time and the deflectiontime curves are recorded on the numerical oscilloscope and then analyzed on a personal computer. In dynamic loading, the direct measurement of the specimen deflection by this optical equipment (based on Doppler effect) is more adequate then the measurement the hammer (or projectile) displacement used in the literature $[9,10]$.

The PMMA Charpy specimens (Fig.1) have the dimensions (40x10x10 mm ${ }^{3}$ ) and $55 \mathrm{~mm}$ for the total length and different crack lengths a (varying between 2 and $5 \mathrm{~mm}$ ). At each velocity, the tests are performed on ten specimens.

At low velocities (less than $1.5 \mathrm{~m} / \mathrm{s}$ ) the toughness is calculated through the measured fracture load. At higher impact velocities (more than $2 \mathrm{~m} / \mathrm{s}$ ), the experimental conditions are not valid for using the classical approach applied above; the influence of inertial effects are discussed in the next section. The new approach consists on the simultaneously measurements of the specimen deflection and the impact load during the fracture test. The maximum load $F_{\max }$ corresponding to the fracture initiation is related to the fracture deflection $\mathrm{u}_{\mathrm{f}}$ as indicated in Fig2. The time to fracture $t_{f}$ is then obtained by means of the load time curve. The effective fracture load is calculated from the fracture deflection and the stiffness of each specimen.

The stiffness $K_{0}$ of the three point bending specimen is statically measured before each test and allows us to calculate the fracture load $\mathrm{F}_{\mathrm{u}}$ from the deflection measurement $\mathrm{u}$ as:

$$
\mathrm{F}_{\mathrm{u}}=\mathrm{K}_{\mathrm{o}} \mathrm{u}
$$

The static stiffness can be used for materials not sensitive to strain rate. Otherwise for the strain rate sensitive materials such as PMMA, we must use the Young modulus values at the strain rate loading. Then the dynamic stiffness $\mathrm{K}(\dot{\varepsilon})$ which is proportional to Young modulus can be calculated as $\mathrm{K}_{0} \mathrm{E}(\dot{\varepsilon}) / \mathrm{E}_{0}$, where $\mathrm{E}_{\mathrm{o}}$ and $\mathrm{E}(\dot{\varepsilon})$ are the Young modulus in static and dynamic loading given in table from a previous paper [11]. The table 1 indicates also the correspondence between the impact velocity and the strain rate as related below (Eq.2).

For the three point bending configuration the strain rate $\dot{\varepsilon}$ is related to the impact velocity $v$ by:

$$
\dot{\varepsilon}=6 W v / L^{2}
$$

which is derived from the well known relation [12] :

$$
\varepsilon=\frac{6 W}{L^{2}} u
$$

where $\varepsilon$ is the maximum strain at the mid span of the specimen. 


\section{3 - Dynamic effects}

It is well known that the conventional impact testers such as Charpy pendulum generate oscillations which can disturb the measurement of the effective load at fracture initiation. The crack initiation point must be determined in order to calculate the dynamic toughness $K_{\text {Id }}$. Crack initiation generally occurs at the maximum load in the case of brittle material and $K_{\text {Id }}$ can be calculated by applying linear elastic fracture mechanics; for Charpy specimen the dynamic toughness is given by [13]:

$$
\mathrm{K}_{\mathrm{Id}}=\frac{3}{2} \frac{\mathrm{FL}}{\mathrm{BW}^{2}}(\pi \mathrm{a})^{1 / 2}\left[1.11-1.55(\mathrm{a} / \mathrm{W})+7.71(\mathrm{a} / \mathrm{W})^{2}-13.53(\mathrm{a} / \mathrm{W})^{3}+14.23(\mathrm{a} / \mathrm{W})^{4}\right]
$$

where F represents the fracture load and the other geometric parameters are defined in Fig. 1. Eq. 4 is valid in a quasistatic loading or if the fracture occurs after times sufficiently large such as a quasistatic loading condition has been reached in the specimen.

Fig. 3 and 4 give typical load-time curve obtained at two different velocities. At slow velocity (Fig.3), the oscillations of the load are relatively small and then the measured fracture load is not perturbed by the dynamics effects. We observe in Fig. 4 (high velocity) that the oscillations have high amplitude which gives an erroneous value of the fracture load. The most important observation is the quasistatic configuration of the specimen during the impact characterized by loading oscillations inherent to inertial effect.

\section{4 - Results and discussion}

Fig. 5 provides all the results obtained in this study where each experimental data corresponds to the average value of the calculation given for three specimens at various crack length.

The dynamic toughness $\mathrm{K}_{1 \mathrm{~d}}$ is calculated through Eq. 4 by using the maximum load obtained in load-time records (see the typical curves in Fig.3 and Fig.4). These $\mathrm{K}_{\mathrm{Id}}$ values are shown by full squares in Fig. 5 . For high impact velocities (more than $2 \mathrm{~m} / \mathrm{s}$ ), this procedure is not valid and we cannot use Eq. 4. The ASTM standard [2] assumes that the time to fracture of the specimen must be larger than three times the period of the oscillations of the impacted specimen. The values indicated inside the dashed line of Fig. 5 are calculated with Eq. 4 but the experimental conditions do not respect the above rule. The high amplitude oscillations during the impact have overestimated the fracture load. The objective of this study is to use the measured displacement which is not perturbed by the oscillations during the impact and to determine the corresponding load $F_{u}$ (Eq.1) which is the effective load responsible of the deflection and then of the fracture itself. Numerical simulations given in a previous paper [5] provide the basis of the physical interpretation of this approach. The $\mathrm{K}_{\mathrm{Id}}$ values calculated with this method are showed by full circles in Fig.5. Other results taken in the literature are reported in this figure (empty square and circles). The observed gap between the results of Fig.5 can be explained by the experimental conditions (specimen geometry, Charpy and Hopkinson loading, initial cracking).

\section{5 - Conclusion}

The present study has pointed out the importance of the measurement of the specimen deflection for calculating the dynamic toughness. At high loading rates, the load-time curve is useful for the determination of the time to fracture and this information can be obtained by electric measurements directly taken at the crack tip of the specimen. The load measurements in this study have illustrated the limitation of the classical approach and give a new performed method for brittle materials. This approach is very simple to apply for non sensitive materials to strain rates. Otherwise we need to characterize the specimen at each impact velocity. Future investigations can study the limitation of this approach for high rates of loading. 


\section{References}

[1] J.F. Kalthoff : On the measurement of dynamic fracture toughness - a review of recent work, Int. J. Fract., 27, 277-98, (1985)

[2] D.R. Ireland : Procedures and problems associated with reliable control of the instrumented impact test, in instrumented impact testing, ASTM STP 563, 3-29, (1974)

[3] V.S. Gopalaratnam, S.P. Shah and R. John :

A modified instrumented Charpy test for cement-based composites

Experimental mechanics, vol 4, issue 2, 102-111, (1984)

[4] P. R. Marur, P. S. Nair and K.R.Y. Simha

Two degrees of freedom modeling of precracked beams under impact,

Engineering Fracture Mechanics Vol. 53, No. 3, pp. 481-491, 1996

[5] S. Sahraoui and J.L. Lataillade

Analysis of load oscillations in instrumented impact testing

Engineering Fracture Mechanics, Volume 60, Issue 4, 437-46, (1998)

[6] Jiang Fengchun, Liu Ruitang, Zhang Xiaoxin, Kenneth S. Vecchio, Aashish Rohatgi

Evaluation of dynamic fracture toughness $K_{\text {Id }}$ by Hopkinson pressure bar loaded instrumented Charpy impact test

Engineering Fracture Mechanics, Volume 71, Issue 3, 279-287(2004)

[7] J.F. Kalthoff, S. Winkler and W. Bohme : A novel procedure for measuring the impact fracture toughness $K_{\text {Id }}$ with precracked Charpy specimen, Journal de Physique, tome 46, 17986, (1985)

[8] P. S. Theocaris and P. Katsamanis, Response of cracks to impact by caustics, Engineering Fracture Mechanics ,Volume 10, Issue 2, 1978, Pages 197-210

[9] S. Sahraoui, J.L. Lataillade, J. Pouyet, N. Skhiri, Fracture of modified epoxy resin at high loading rates, Polymer Testing, 7, 269, (1987)

[10] W. Grellmann, S. Seidler, W. Hesse, Procedure for Determining the Crack Resistance Behaviour Using the Instrumented Impact Test

In: Grellmann, W., Seidler, S. (Eds.) Deformation and Fracture Behaviour of Polymers, Springer Berlin Heidelberg 2001, 71-86

[11] S. Sahraoui and J.L. Lataillade, Deformation and fracture of PMMA at high rates of loading, J. Applied Polymer Science, vol. 51, 1527-32, (1994)

[12] S. Timoshenko : “Strength of materials”, Krieger Pub. Company, New York (1976)

[13] G.C. Sih, Handbook of stress intensity factors, Lehigh University, Bethlehem, PA, (1973) 


\section{CAPTIONS FOR ILLUSTRATIONS}

Fig. 1:

Three points bending Charpy specimen and schematic of the experimental arrangement.

Fig. 2 :

Schematisation of the deflection to fracture measurement.

Fig. 3 :

Typical load-time and displacement-time curves of brittle material ( $\mathrm{v}=1.2 \mathrm{~m} / \mathrm{s}, \mathrm{a}=2 \mathrm{~mm})$

Fig. 4 :

Typical load-time and displacement-time curves of brittle material $(\mathrm{v}=2.3 \mathrm{~m} / \mathrm{s}, \mathrm{a}=2.5 \mathrm{~mm})$

Fig. 5 :

Dynamic toughness $\left(\mathrm{MPa} \mathrm{m} \mathrm{m}^{1 / 2}\right)$ vs strain rate $\left(\mathrm{s}^{-1}\right)$

Table :

Young modulus versus strain rate and impact velocity [9] 


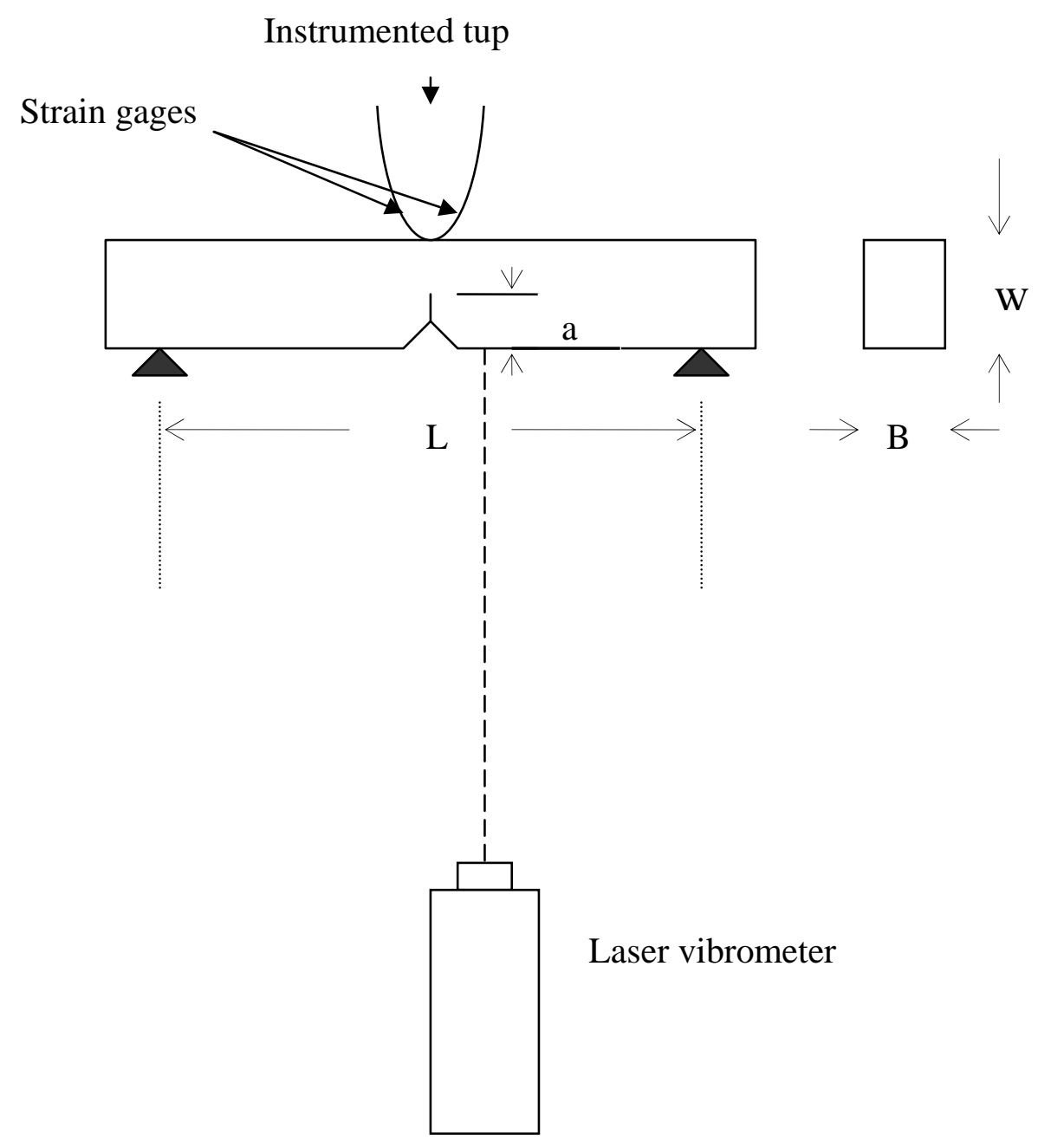

Figure 1 


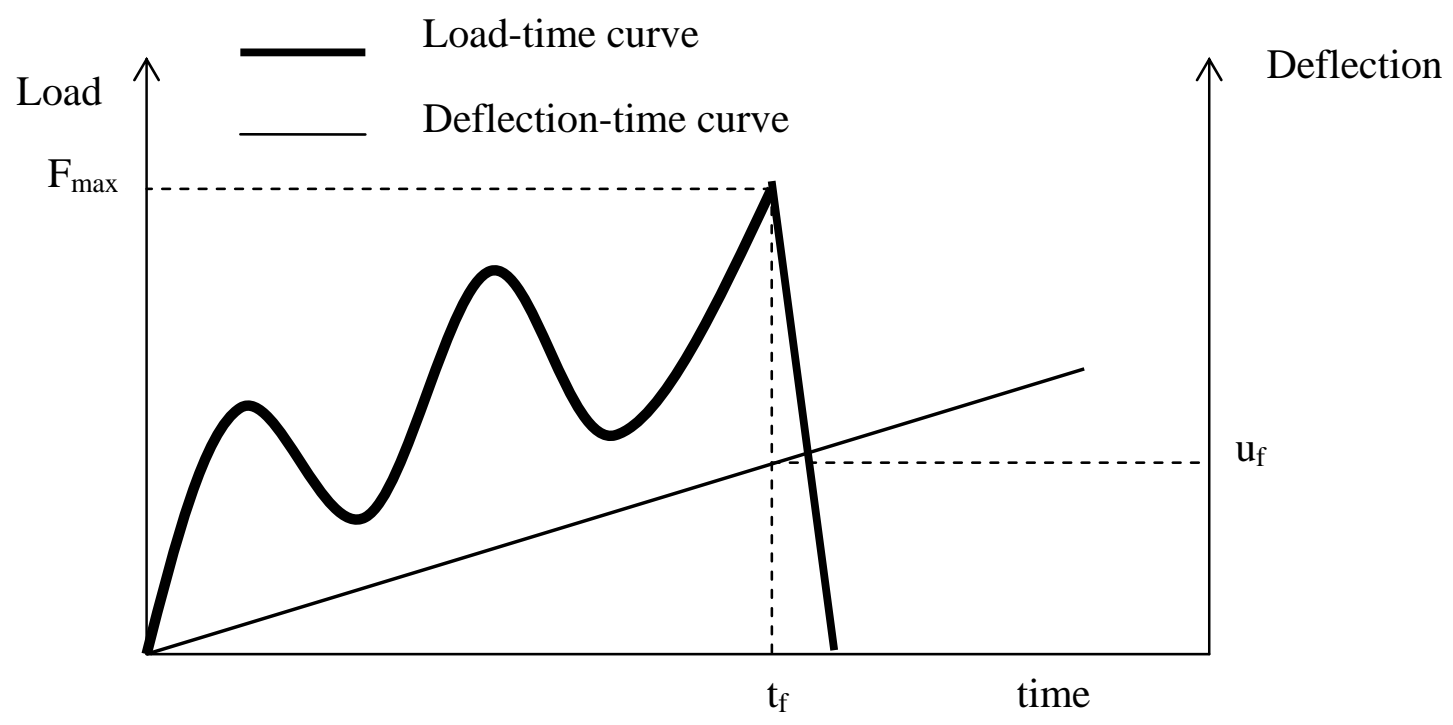

Figure 2 


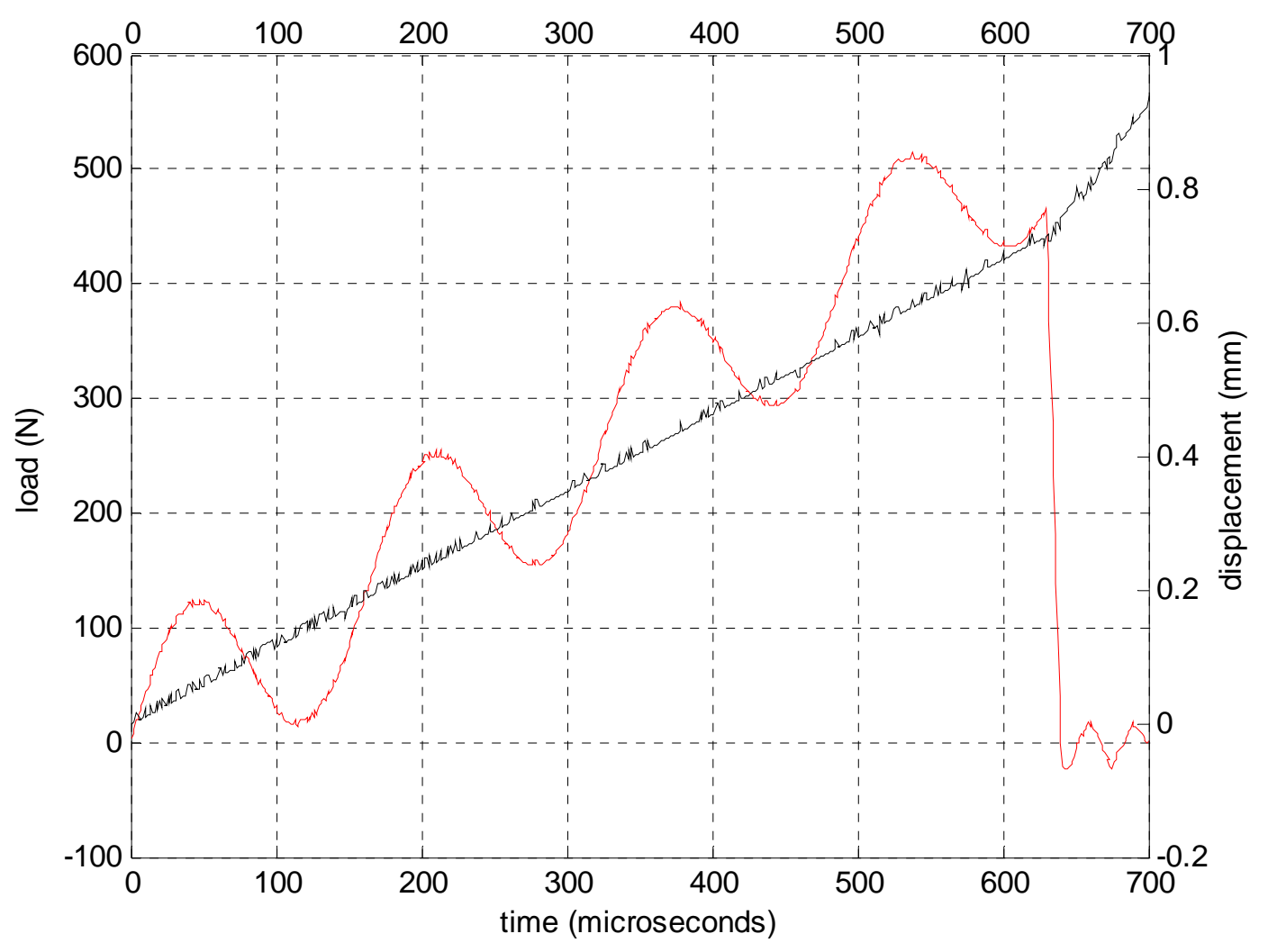

Figure 3 


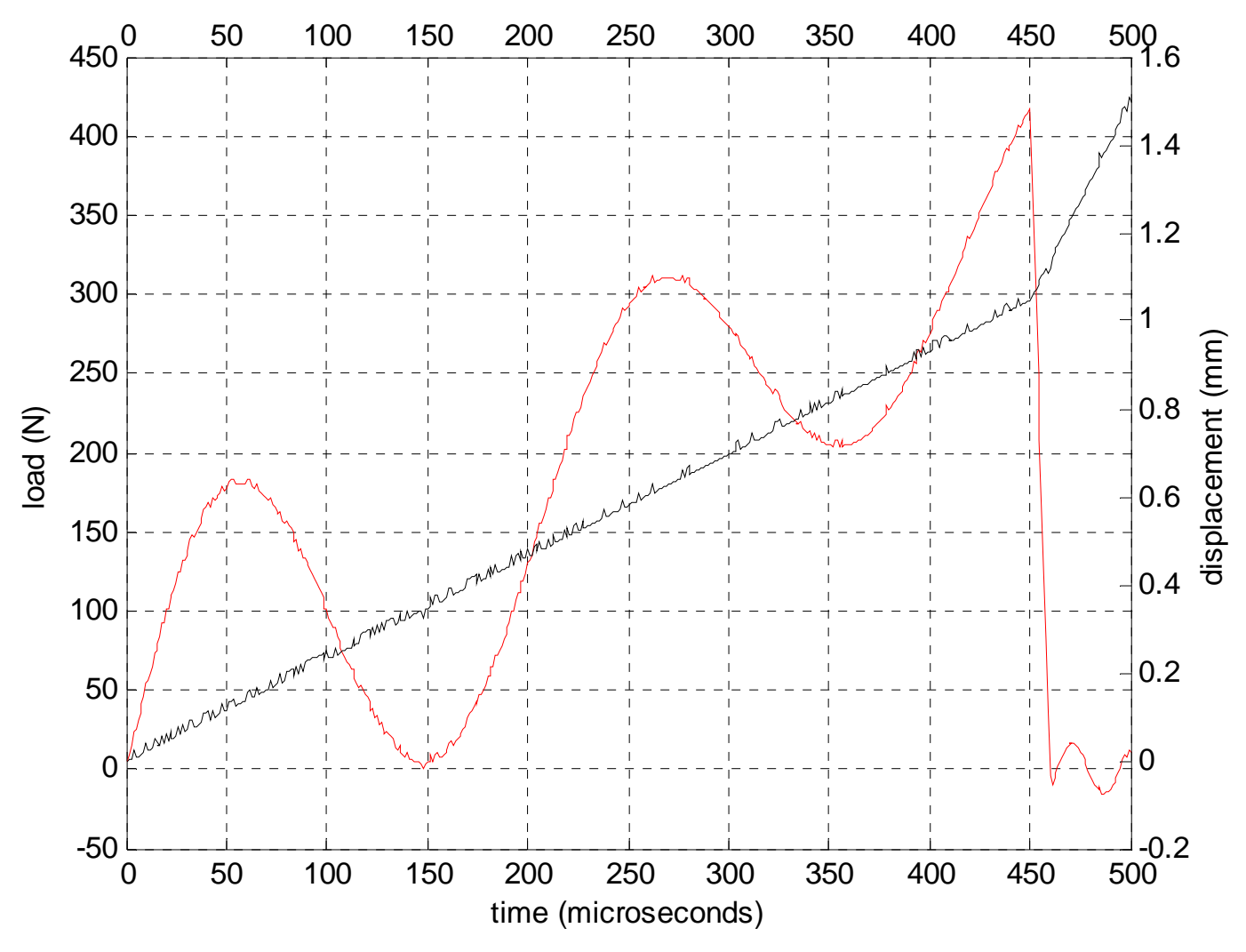

Figure 4 


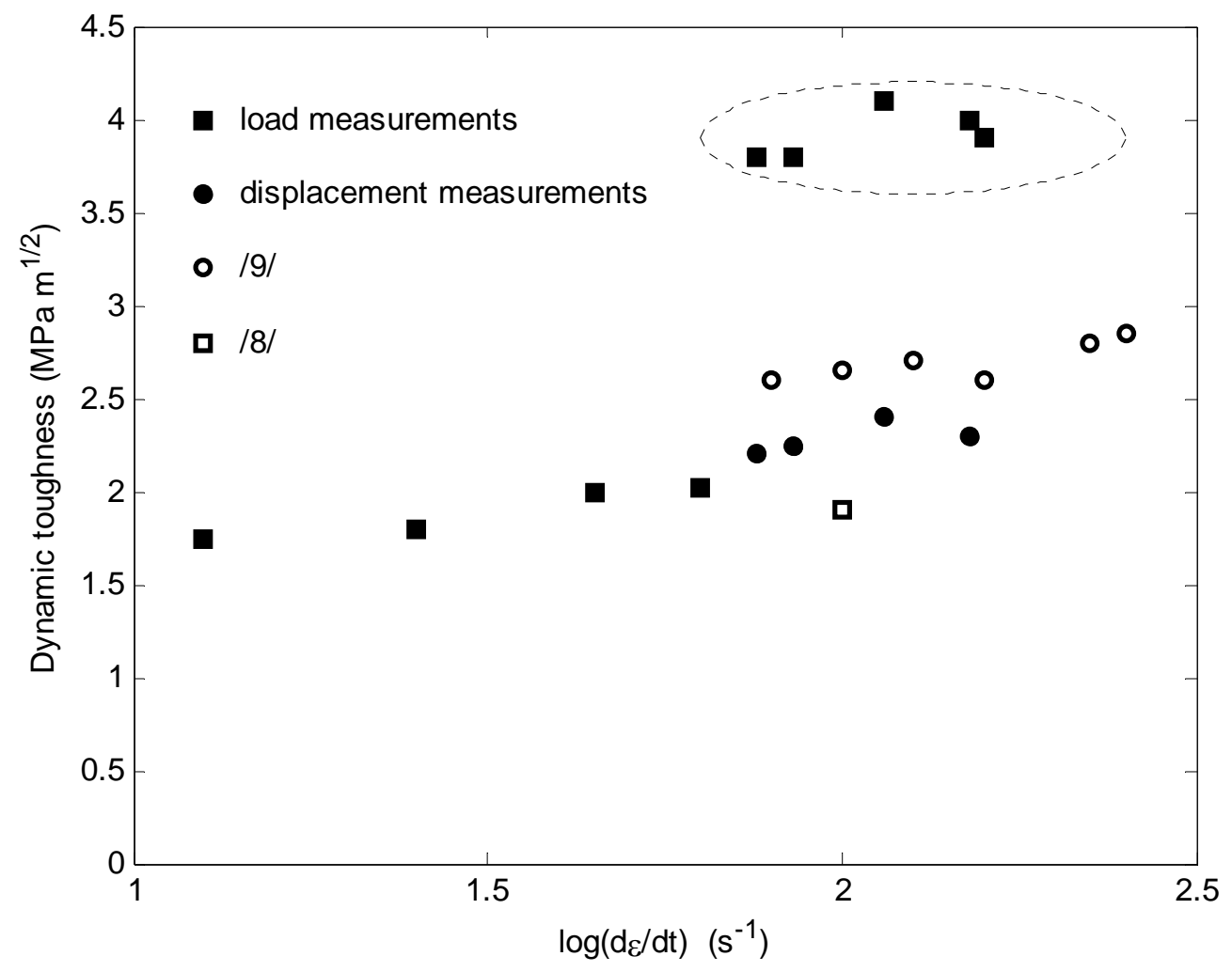

Figure 5 


\begin{tabular}{|c|c|c|c|c|}
\hline $\mathrm{v}(\mathrm{m} / \mathrm{s})$ & $\begin{array}{c}\text { static } \\
\text { loading }\end{array}$ & 2.3 & 3.1 & 4 \\
\hline $\log \dot{\varepsilon}\left(\mathrm{s}^{-1}\right)$ & -2 & 1.93 & 2.06 & 2.18 \\
\hline $\mathrm{E}(\mathrm{GPa})$ & 3.4 & 5.3 & 5.4 & 5.5 \\
\hline
\end{tabular}

Table 